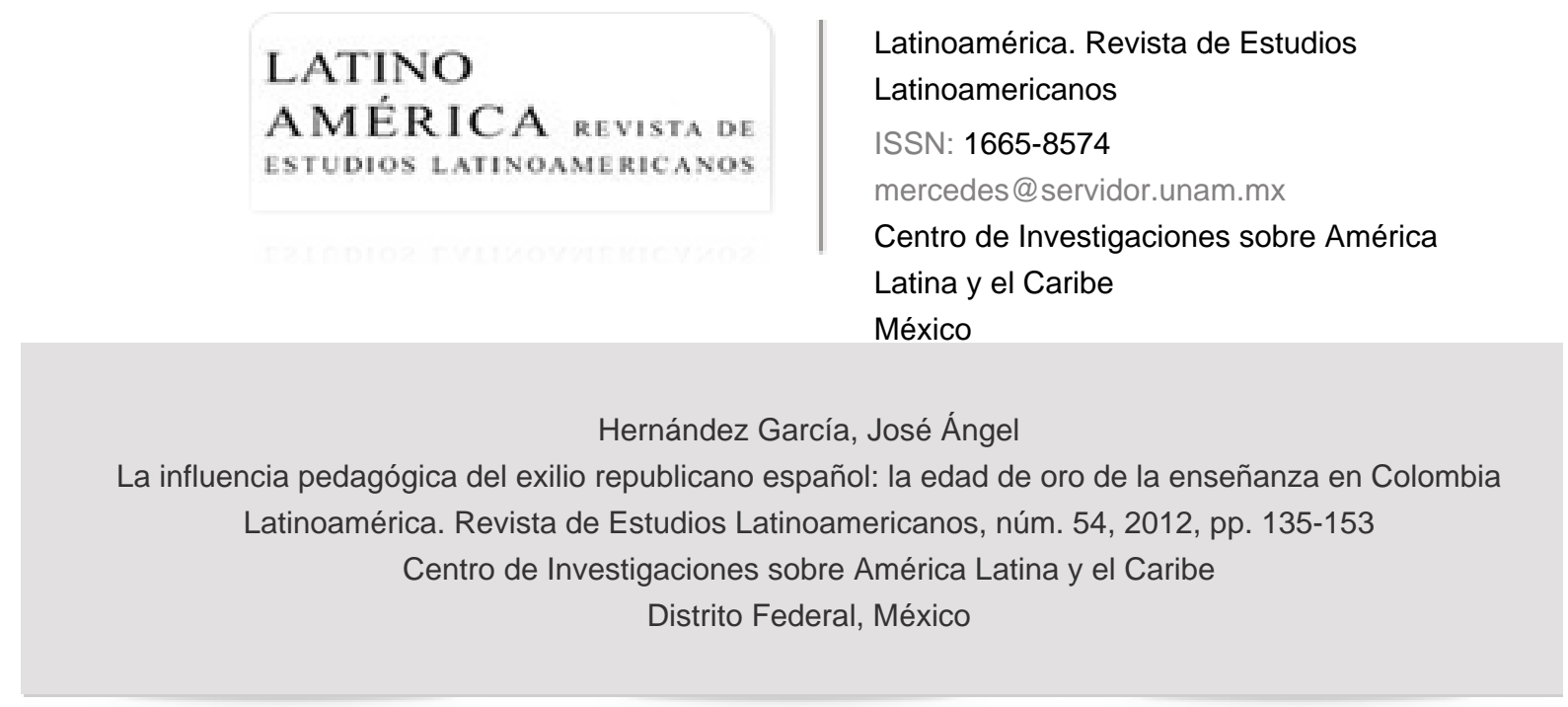

Disponible en: http://www.redalyc.org/articulo.oa?id=64023055006

Cómo citar el artículo

- Número completo

- Más información del artículo

- Página de la revista en redalyc.org

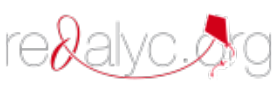

Sistema de Información Científica

Red de Revistas Científicas de América Latina, el Caribe, España y Portugal Proyecto académico sin fines de lucro, desarrollado bajo la iniciativa de acceso abierto 


\section{La influencia pedagógica del exilio republicano español: la edad de oro de la enseñanza en Colombia}

José Ángel Hernández García*

Resumen: La llegada de exiliados españoles a Colombia como consecuencia de la Guerra Civil española (1936-1939) supuso un florecer del mundo educativo colombiano, hasta ese momento apático y anticuado. El que entre los exiliados hubiera una cantidad considerable de docentes y pedagogos explicaría esta "Edad de Oro" de la educación en Colombia. La apuesta decidida de las instituciones del Estado por las nuevas técnicas pedagógicas que representaban los pedagogos españoles fue fundamental para el despegue de la educación en Colombia en los años treinta, cuarenta y cincuenta, abandonando viejas prácticas educativas. Este artículo intenta explicar el devenir de estos exiliados desde el punto de vista laboral y vital, así como de las instituciones en que compartieron sus conocimientos pedagógicos en Colombia.

Palabras Clave: Exilio, España, Colombia, Pedagogos.

ABSTRACT: The arrival of Spanish exiles to Colombia as a result of the Spanish Civil War (1936-1939) meant a flowering of the Colombian educational world, until then apathetic and outdated. The fact that among the exiles there were a significant number of teachers and educators explains this "golden age" of education in Colombia. The firm commitment of state institutions for the new techniques of the Spanish was central to the launch of education in Colombia in the thirties forties and fifties. Old educational techniques were abandoned. This article attempts to explain the fate of these exiles, from a standpoint of their labor and living conditions, as well as institutions with which they shared their pedagogical knowledge in Colombia.

Key words: Exile, Spain, Colombia, Educators.

Universidad de la Sabana, Colombia (jose.hernandez@unisabana.edu.co). 
Hernandez_revista latinoamerica 06/06/12 11:54 Página 136

José Ángel Hernández García

T lama la atención el que si la emigración a Colombia como consecuencia de la Guerra Civil española fue muy reducida, el aporte intelectual y sobre $\mathcal{U}$ todo pedagógico de estos exiliados políticos fuera tan ingente.

El perfil del emigrante español a Colombia después del conflicto fraticida en la "Vieja Piel de Toro", obviando la emigración de religiosos, es eminentemente técnica. Encontramos en las listas de solicitud de visas para Colombia, y desde 1936, una muy vasta proporción de profesionales liberales, técnicos, industriales, etc. ${ }^{1}$ En el rubro de profesionales liberales encontramos un alto porcentaje de universitarios, muchos de ellos se habían ejercido como docentes en España, y había una proporción de pedagogos considerables. Además, por las circunstancias propias del país que los recibía, en este caso Colombia, muchos de estos transterrados al no encontrar ocupación para su preparación técnica y con un alto nivel intelectual, se decantaron por la enseñanza. Para lo anterior contaron con el apoyo total del ministro de Educación de la época, Germán Arciniegas. Un personaje siempre presto al apoyo de la causa republicana durante el conflicto en España y luego a fungir como introductor de los españoles que iban llegando a Colombia cuando las armas gubernamentales ya mostraban signos de no poder ganar la contienda.

En esta labor de promoción de fomento de la emigración intelectual republicana española, Arciniegas contó con un franco opositor, su compañero de gabinete, Luis López de Mesa, ministro de Exteriores. Aún recuerdan algunos exiliados el comentario del canciller colombiano cuando le recomendaban algún peticionario español de visa: "¿Quién me garantiza que no es un bombista anarquista o comunista?".

1 Para mayor información, véase: V. Llorens, En la emigración republicana", Barcelona, Taurus, 1978, p. 172. Concretamente el capítulo referido a Educación y Pedagogía de C. Sainz de la Calzada.

2 Esta percepción respecto a los exiliados republicanos españoles era, paradójicamente, común entre los liberales colombianos, a los que se suponía más receptivos con estos refugiados políticos. Así lo ratifican los que lo sufrieron como Paulino Gómez Basterra, hijo del último ministro de la Gobernación de la República Española. Paulino Gómez Sainz, exiliado en Colombia. El enfrentamiento por el tema de los refugiados entre el canciller López de Mesa y el ministro de Educación, Germán Arciniegas, era vox pópuli entre los exiliados, pero también en las ins- 
Hernandez_revista latinoamerica 06/06/12 11:54 Página 137

La INFLLENCIA PEDAGÓGICA DEL EXILIO REPUBLICANO ESPAÑOL: LA EDAD DE ORO DE LA ENSEÑANZA EN COLOMBIA

Lo cierto es que el filtro de la emigración republicana española por parte de las autoridades colombianas de la época fue concienzudo y se centró en la concesión de permisos de emigración, eso sí pocos, para personas con un alto grado de preparación intelectual y sin un destacado pasado revolucionario, cuestión esta que causaba auténtico pavor, tanto a los liberales en el gobierno, como, sobre todo, a los conservadores en la oposición. Recordemos que esto se dio a pesar del nominal, más que práctico, apoyo a la República española de los gobiernos liberales de López y Santos, que presagiaban una mayor receptividad de los exiliados republicanos. Las autoridades liberales fueron más asequibles a la presión conservadora y a una parte importante de la opinión pública colombiana que veía en los posibles demandantes de visas como unos "rojos peligrosos y asesinos de monjas y curas". ${ }^{3}$

El intento de López Pumarejo de, según palabras del liberalismo, "modernizar las estructuras del Estado" - o de manera oficial a través de la frase "la revolución en marcha" que se convirtió en el eslogan de la presidencia de López y que demandaba de burócratas preparados para afrontar los cambios que se preveían - vio en los españoles republicanos recién arribados una fuerza intelectual e ideológica que no se podía obviar. Era evidente que entre las reformas necesarias para los liberales, la más necesaria era la de la educación y que para ejecutarla no era suficiente el aporte de los intelectuales y pedagogos autócto-

tituciones del Gobierno. Sirva de ratificación el intento de Germán Arciniegas por traer al país al filósofo Stefan Zweig, exiliado, huyendo de las hordas nacional socialistas, en Brasil. La oposición tenaz de López de Mesa no hizo posible la arribada del prestante pensador que terminó suicidándose en 1941 quizá esperando un visado hacia Colombia y desesperando por ello.

3 Laureano Gómez, jefe indiscutible del Partido Conservador, se refería a la lucha que se daba en España en los siguientes términos: "El carácter decisivo de la lucha no se lo ha ocultado a nadie, si la marejada comunista llega a preponderar sobre la España Católica, las turbulentas aguas inundarán de rechazo la patria de San Luis y amenazarán con gravedad inaudita las instituciones actuales de Alemania e Italia", en Diario el Siglo, 6 de junio, 1937.

Tampoco ayudaban a la causa de la emigración republicana las noticias de asesinato y tortura de unos religiosos colombianos de la orden hospitalaria por los milicianos en agosto de 1936. P. Roberto M. Tisnes J. CMF, Los mártires colombianos de la orden hospitalaria de San Juan de Dios, Santa Fe de Bogotá, Orden hospitalaria de San Juan de Dios, Curia Provincial. 
Hernandez_revista latinoamerica 06/06/12 11:54 Página 138

José Ángel Hernández García

nos. Como dijo el presidente en su toma de posesión: "No tenemos verdaderos maestros en la enseñanza primaria y secundaria..."

Para López las llamadas universidades colombianas no eran más que academias, asi "la situación nos obliga a buscar profesionales extranjeros". ${ }^{4}$

Seguramente López no pensó en los españoles como primera opción de pedagogos foráneos, la francofilia y la anglofilia de la oligarquía colombiana a la que pertenecía López era grandísima. Además, los prejuicios en contra de la vieja potencia colonial, en este caso española, nos lleva a pensar así, pero la Guerra Civil española con el exilio republicano consiguiente hizo que fuera la opción más factible para la administración lopista y luego santista.

Los consulados colombianos, en Francia y Bélgica, especialmente, comenzaron a informar al Palacio de San Carlos, sede de la cancillería colombiana, de una gran cantidad de peticionarios visados para Colombia de españoles republicanos atrapados en Francia que no podían salir del país sin un permiso o visado. El Ministerio de Exteriores colombiano se mostraba poco receptivo con la llegada de extranjeros, así que decidió, como mal menor, permitir la llegada de algunos exiliados españoles con expedientes laborales prestantes en el ámbito de la academia, de la ciencia y en general de la cultura, obviando descaradamente a los que tenían marchamo revolucionario y a los que se suponían peligrosos desde el punto de vista político por sus ideas de izquierda.

Esto suele ser desconocido por algunos historiadores del exilio republicano en Colombia que prefieren dejar de lado este espinoso asunto en aras de un relato más "buenista" sobre la actuación con el exilio español de las autoridades colombianas de la época. ${ }^{5}$

4 Jaime Jaramillo Uribe, "La educación en los gobiernos liberales 1930-1946", en Nueva Historia de Colombia, t. IV, Bogotá, 1989, p. 89.

5 Así se comprueba que quizá la única autora en España que ha tratado de manera monográfica el exilio español en Colombia es María Eugenia Martínez Gorroño. La autora no obvia que los exiliados fueron "seleccionados", pero no plantea lo discriminatorio de esta criba, lo que hizo, por citar un ejemplo, que hubiera más exiliados republicanos españoles en la República Dominicana del terrible dictador Trujillo que con los presidentes liberales López o Santos, en Colombia. "La educación en la Colombia Liberal de los años 30 y 40: la trascendente contribución 
Hernandez_revista latinoamerica 06/06/12 11:54 Página 139

La INFLLENCIA PEDAGÓGICA DEL EXILIO REPUBLICANO ESPAÑOL: LA EDAD DE ORO DE LA ENSEÑANZA EN COLOMBIA

\section{LLEGADA DE LOS PRIMEROS EXILIADOS Y SU PERIPECIA PEDAGÓGICA}

Durante el primer gobierno de Alfonso López Pumarejo empezaron a llegar los primeros exiliados a Colombia, en este caso vascos que, después del conocido Pacto de Santoña, habían abandonado la lucha contra los franquistas. Dos personajes destacan entre los demás, Francisco Abrisketa y Andrés Perea Gallaga.

La contribución a la educación de estos dos prestantes representantes del nacionalismo vasco merece ser destacada. Francisco, "Patxi", Abrisketa ${ }^{6}$ había cursado en España los estudios de economía en la universidad de Deusto y había ingresado en el Banco de Vizcaya. Al llegar a Colombia desempeñó cargos en el Banco de la República y otras entidades financieras, debido a su preparación.

Durante años fue profesor de Estadística y Economía en la Universidad Nacional de Colombia así como en la Universidad Pontificia Javeriana, ambas sitas en Bogotá. Muchos de los que luego ocuparon cargos de dirección económica, tanto en un nivel estatal como privado, fueron alumnos de Abrisketa.

Abrisketa publicó o fomentó la publicación de varios libros de reivindicación vasquista, normalmente editados en Caracas o por la editorial Ekin de Buenos Aires. Su biblioteca sobre el libertador Simón Bolívar es considerada como una de las más extensas en Europa, actualmente está repartida entre la Universidad de Deusto, su alma mater, y el convento de los padres benedictinos de Ataún en Guipuzcoa. La llegada de esta colección a su País Vasco natal no fue fácil y se aceptó por parte del gobierno colombiano cuando Abrisketa se comprometió a donar su biblioteca de economía a la Pontificia Universidad Javeriana de la capital bogotana regentada por la Compañía de Jesús y donde él había fungido como docente.

del exilio español consecuencia de la Guerra Civil, 1936-1939", en Revista Migraciones y Exilios, núm. 4, Universidad de Educación a Distancia, unED, Facultad de Geografía e Historia, Departamento de Historia Contemporánea, 2003, pp. 9-30.

6 Quizá el compendio de la peripecia vital y política más enjundioso de Francisco Abrisketa se puede encontrar en R. Basurto Larrañaga [coord.], "Homenaje a Francisco de Abrisketa", en Frantzisko Abrisketa-ri Omenaldia, Sociedad Bolivariana del País Vasco, 1993. 
Hernandez_revista latinoamerica 06/06/12 11:54 Página 140

José Ángel Hernández García

Tal fue su contribución al desarrollo del país que lo acogió que se le concedió la Cruz de Boyacá, máxima condecoración de la República de Colombia.

El exilio vasco no termina con Patxi Abrisketa, otro destacado representante de esta peculiar diáspora dentro de la general republicana es Andrés Perea Gallaga, quien se dedicó también a la enseñanza y realizó el primer censo de Colombia, con el que ganó la máxima condecoración del país, la Cruz de Boyacá Su hijo José Perea Sasiain fue profesor en la Facultad de Medicina de la Universidad Nacional, principal centro de educación superior estatal y que en 1934, por normas inspiradas por el presidente López Pumarejo, se configuró con la estructura actual. Gran amigo de los derrotados en la guerra fraticida que se había dado en la Península ibérica, contó con ellos para conformar el plantel docente desde la llegada de los primeros republicanos hispanos. Uno de ellos fue el vasco Juan Antonio Irazusta, diputado en la época republicana, se dedicó a la literatura durante su exilio en Colombia y escribió dos novelas cuya temática se centraba en lo vasco, Joañixio y Bizia Garratzada, publicadas por la editorial Vasquista Ekin. Finalmente terminó sus días como religioso en Perú.

A finales de 1937 y principios de 1938, el Ejército Nacional conquistó amplias zonas de España y comenzó el exilio máximo, unos cuantos eligieron Colombia como destino para comenzar su nueva singladura vital.

El embajador republicano en Bogotá, Rafael Ureña, empezó a informar a Madrid de estas arribadas ya para 1937, pero sobre todo para principios de 1938, cuando la colonia de exiliados ya contaba con prestantes personajes que contribuirían de manera significativa al desarrollo académico e intelectual de Colombia, una vez salvadas las oposiciones oficiales eran ya motejados "de hombres ilustres, alejados de la política y entregados a sus disciplinas intelectuales [...]

7 Rafael Ureña fue nombrado embajador, el primero con tal categoría en Colombia, tomó posesión de la representación diplomática a finales de mayo de 1938. Rápidamente empezó a remitir informes al Ministerio de Estado en España sobre la situación de la colonia de exiliados españoles. En honor a la verdad, sus informes no fueron muy optimistas sobre la fe en la victoria de la causa republicana entre la colonia residente en Colombia, así como del apoyo del Gobierno del presidente colombiano Eduardo Santos a la misma causa. En el Archivo General de la Administración en Alcalá de Henares, Madrid, España, se encuentra una carpeta a nombre de "Rafael Ureña", la 3114, que ratificaría lo dicho.

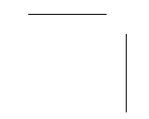


Hernandez_revista latinoamerica 06/06/12 11:54 Página 141

LA INFLUENCIA PEDAGÓGICA DEL EXILIO REPUBLICANO ESPAÑOL: LA EDAD DE ORO DE LA ENSEÑANZA EN COLOMBIA

hombres de estudio, profesores e investigadores, que buscan un sitio tranquilo para continuar sus trabajos, lejos de la dura presión dictatorial y en el ambiente acogedor y propicio de un pueblo libre".

LuIS DE ZulueTA, EL MÁS DESTACADO POLÍTICO Y PEDAGOGO DEL EXILIO REPUBLICANO EN COLOMBIA

Luis de Zulueta Escolano es, sin lugar a dudas, el más prestante de los exiliados republicanos españoles en Colombia, avalado por los cargos y responsabilidades políticas que ostentó en España antes de su forzado exilio. Fue diputado de la República, ministro y embajador, además de uno de los principales teóricos de la pedagogía contemporánea española.

Zulueta era considerado un moderado dentro de los círculos de la izquierda española e incluso por la derecha que veía en su porte y sus maneras diplomáticas alguien distinto al "miliciano" común. Estos modales y prestancia le hicieron el personaje más idóneo para desempeñar cometidos diplomáticos ante la Alemania hitleriana o en la Santa Sede, el último destino diplomático de este republicano liberal-burgués y católico. Al ser desalojado violentamente del Palazzo de Spagna, sede de la Embajada española en el Vaticano, por los franquistas y con la aquiescencia de las autoridades fascistas italianas, Zulueta decidió no volver a una España ya en plena contienda, y optó por el exilio el 30 de septiembre de 1936.

Eduardo Santos, quien luego sería presidente colombiano, al saber de su exilio en París, le ofreció emigrar a Colombia, y le propuso un contrato como colaborador en el periódico El Tiempo de su propiedad.

Luis de Zulueta había sido profesor de la Escuela Superior de Magisterio en España, lo que lo hacía personaje idóneo para laborar en el ámbito educativo en Colombia, así pronto le ofrecieron un puesto en el Ministerio de Educación colombiano.

${ }^{8}$ El Tiempo, 14 de abril, 1939.

latino @mérica 54

(Méxxco 2012/1): 135-153 141 
Hernandez_revista latinoamerica 06/06/12 11:54 Página 142

José Ángel Hernández García

Su llegada a Colombia no pasó inadvertida, incluso los conservadores profranquistas, es decir la mayoría, le desearon parabienes, no sin antes advertir al ex ministro de Estado

[...] para que por encima de cualquier otra conveniencia, se mantenga en su línea de intelectual puro, le pedimos, anticipadamente, que desoiga las sirenas partidistas que el Ministerio de Educación pretenderán poner su pluma al servicio de la república liberal, faltos, como se hallan, de valores siquiera medianos. El debe sentirse en esta ciudad como en la prolongación espiritual de una de esas resacas y melancólicas urbes empotradas en Castilla que hoy lucha bravamente por la reconquista de los blasones fundamentales, amenazados tan rotundamente por la barbarie rusa. Confiamos en el resurgir de España, que será 'La edad de oro' de la que habló a sus discípulos en la residencia de estudiantes el mismo don Luis de Zulueta, bienvenido.

Sirva lo anterior como ejemplo de la fama de fino intelectual y pedagogo que precedía a este amigo de Azaña y de Unamuno. Recordemos que había sido catedrático de la Historia de la Pedagogía en España y que si bien abandonó la enseñanza efectiva en 1910 al ser elegido diputado a cortes por Barcelona, no descuidó nunca el interés por la pedagogía como demuestran sus publicaciones sobre el tema después de ese año. ${ }^{10}$

Lo cierto es que la vida de Zulueta y su familia si no fue feliz, sí apacible, sobre todo por la buena remuneración de sus regulares colaboraciones en el periódico liberal El Tiempo. Sin embargo, y no por necesidad, decidió seguir ejerciendo la profesión docente en distintas instituciones educativas de Bogotá como la Universidad Nacional, la Escuela Normal Superior, el Instituto Pedagógico Nacional o la Universidad de los Andes, esta última que él ayudó a fundar.

Hasta 1960, la vida de Zulueta transcurrió sin especiales sobresaltos, año en que Zulueta decidió cambiar de aires al partir hacia Estados Unidos, donde murió a los 64 años de edad. Se acababa así la vida del que, sin ningun titubeo,

9 El Siglo, 11 de marzo, 1937.

${ }^{10}$ Entre otras destacaremos El alma de la escuela (1910), El Maestro (1924) y El ideal de la educación (1942). 
fue el personaje más destacado de un exilio que lo obvio y lo sometió a una marginación que aún se mantiene en los trabajos sobre el exilio republicano. ${ }^{11}$

\section{EL GIMNASIO MODERNO, INSTITUCIÓN SEÑERA}

DE LA EDUCACIÓN PRIMARIA COLOMBIANA

Aunque el ámbito de actuación académica de los exiliados españoles estuvo muy centrado en la Educación Superior, también hubo españoles que se ocuparon de la formación primaria de la oligarquía liberal y librepensadora, sobre todo a través del elitista Gimnasio Moderno, fundado en 1914.

Agustín Nieto Caballero, fundador del Gimnasio Moderno y que luego en reconocimiento a su labor educativa fue nombrado ministro de Educación, pensaba que era necesaria la creación de una institución pedagógica que formara una nueva "aristocracia colombiana", para ello viajó a Europa, sobre todo a Francia y España, con la misión de informarse sobre los nuevos métodos pedagógicos, destacando el conocido como Montessori. En uno de sus viajes a Madrid quedó gratamente impresionado por los intentos de la nueva administración republicana de ofrecer a sus alumnos en las distintas escuelas un sistema educativo más práctico y moderno de la que la Institución Libre de Enseñanza sería el ejemplo más destacado y emblemático. Por sugerencia de dicha institución, Nieto Caballero contactó con varios educadores para un posible desplazamiento a Colombia que permitiera, junto con otros colegas colombianos, empezar la singladura del revolucionario Gimnasio Moderno. Los profesores elegidos fueron Pau Vila i Dinarés, Miquel Fornaguera y Flora González. De los tres, Pau Vila será el encargado de coordinar la nueva etapa del Gimnasio Moderno. Su ex-

${ }^{11}$ Un estudio pormenorizado sobre la figura política y pedagógica de Zulueta está en M. de C. Crespo Pérez, "Luis de Zulueta, político y pedagogo", en Revista Complutense de Educación vol. 7, núm. 1, Madrid, Servicio Publicaciones Universidad Complutense, 1996. También Carmen de Zulueta, Luis de Zulueta, Alicante, Instituto de Cultura Gil-Alvert, 1996 y C. Zulueta Cebrián, "Mi viaje a Cuba, una reeducación sentimental", en Revista Historia 16, año XXV, núm. 312, abril de 2002. 
Hernandez_revista latinoamerica 06/06/12 11:54 Página 144

José Ángel Hernández García

periencia era sumamete valorada y conocida en los ambientes pedagógicos españoles, lo que lo hacía ser el líder natural para esta tarea. ${ }^{12}$

Durante los primeros momentos de su actividad renovadora en el Gimnasio Moderno, Vila recibió una carta de un paisano catalán, que enterado del proyecto, ofrecía sus servicios y su experiencia, era Miquel Fornaguera Ramón.

Miquel Fornaguera se había formado como docente en la Escola de Mestres, de la ciudad Condal, cuya dirección en ese momento estaba a cargo de Juan Bardina, miembro de la generación del '98 y amigo y correligionario de Ginés de los Ríos. De la Institución Libre de Enseñanza tomó Barcina los parámetros a seguir en su escuela. En 1912 Barcina hizo una visita a París para especializarse en las nuevas técnicas pedagógicas y eligió entre sus pupilos a Fornaguera para que le acompañara durante los dos años que duraba la estancia. Al estar en la capital gala, Fornaguera empezó a interesarse por Colombia y seguramente llevado por su espíritu aventurero decidió emigrar al país sudamericano en 1915. La idea era dedicarse a la agricultura, concretamente al cultivo de tomates, junto con otros cinco compañeros. Rápidamente se dio cuenta de que el cultivo de hortalizas no era lo suyo y decidió marcharse a Medellín. Estando en la capital antioqueña se enteró del proyecto de regeneración pedagógica del Gimnasio Moderno y escribió ofreciendo sus servicios. Pau Vila enseguida lo llamó a su lado, recordemos que Vila fue el rector del Gimnasio Moderno de 1915 a 1917 y que tenía carta blanca para contratar a cualquier pedagogo que él considerara necesario.

${ }^{12}$ Pau Vila i Dinarés nació en Barcelona en 1881, murió a punto de cumplir un siglo de vida en su ciudad natal. Estudió en el Instituto de Ciencias de Ginebra, por lo que estaba muy al tanto de las modernas técnicas pedagógicas del momento. Al terminar su cometido en Colombia, regresó a España en 1918, para volver como exiliado a causa de la derrota de las armas republicanas en España y por intercesión del presidente Eduardo Santos. La Escuela Normal Superior lo acogió como profesor de Geografía y por supuesto "su" Gimnasio Moderno. Para algunos sería el más destacado miembro de la geografía moderna en el mundo hispano, después de la disolución de la Escuela Normal Superior, emigró a Venezuela donde siguió desempeñándose como geógrafo. Volvió a España después de la muerte del dictador Francisco Franco y murió en 1980. 
Fornaguera fue nombrado director de Internos, entre las actividades que fomentó destaca el "excursionismo escolar", que según él era el mejor método para canalizar el vitalismo juvenil y romper con la indolencia y apatía de métodos pasados.

En 1924, en plena dictadura de Primo de Rivera, regresó a Barcelona, pero salió huyendo de aquel régimen para trasladarse de nuevo a Bogotá, donde retomó su actividad en el Gimnasio Moderno, hasta que le ofrecieron la vicerrectoría de la Universidad del Cauca en Popayán. Ahí se enteró de la victoria electoral de las izquierdas en España y partió a Barcelona en 1933, donde se dedicó a la docencia hasta la victoria de las tropas franquistas, momento en que decidió volver de nuevo a Colombia. Hasta su muerte en 1980 Fornaguera se desempeñó como docente, además del Gimnasio Moderno, en los prestigiosos colegios Refus, Boston, Nemesio Camacho y en el Instituto de Segunda Enseñanza de Santa Marta.

Su compromiso político, republicano y catalanista nunca menguó, sirva de ejemplo la carta que dirigió al director del diario colombiano El Espectador en 1977 como muestra palmaria de ello:

[...] como colaboración al aniversario de la proclamación de la República Española, me permito enviarle estos papeles. Dado el hecho de que a pesar del ruidoso éxito del 'referéndum' realizado por la dictadura en España, en estos días se desencadena nuevamente una ola de detenciones y persecuciones de las libertades humanas y sociales, he creído de actualidad publicar la traducción de los versos que ganaron la 'Englatina de oro' en los juegos florales de la lengua catalana que se celebraron en París en el año 1965 [...] puesto que después de 35 años de paz, aún no se puede celebrar en Barcelona. Podrán publicarse en la hoja dominical como nuevo estilo literario [... los catalanes, españoles del mundo libre se lo agradecerán $[\ldots] .^{13}$

${ }^{13}$ Nota mecanografiada del archivo familiar de los Fornaguera, en "La pedagogía moderna desde una perspectiva transnacional: Miguel Fornaguera, un libre pensador catalán en Colombia", leída por Alejandro Álvarez Gallego como ponencia en el IX Congreso Iberoamericano de Historia de la Educación Latinoamericana: educación, autonomía e identidad en América Latina Río de Janeiro, 16 al 19 de noviembre de 2009. En el Magazine dominical de El Espectador se publicó lo demandado por Fornaguera, es decir los poemas de Coloma Leal. 
Hernandez_revista latinoamerica 06/06/12 11:54 Página 146

José Ángel Hernández García

Tanto Fornaguera como Vila fomentaron y avalaron la arribada de exiliados republicanos a Colombia, ayudando a su ubicación laboral en el país que los acogió, sobra decir que la mayoría lo hicieron en el gremio docente, dejando muy alto el pabellón del exilio español no sólo en Colombia, sino en Iberoamérica.

\section{LA REVISTA DE INDIAS, REVISTA DE EXTENSIÓN CUITURAL} DEL Ministerio De EduCACIÓN

En 1936 y casi coincidiendo con el estallido de la Guerra Civil española, aparecía en Colombia la Revista de Indias, una publicación que marcaría un hito en la cultura colombiana y que contó con la colaboración inestimable de prestantes exiliados españoles.

Había nacido esta revista para sustituir a la pionera Senderos que patrocinada por la Biblioteca Nacional y dirigida por Daniel Samper había tenido una limitada difusión debido a su vocación elitista más que de difusión de cultura.

La reforma de la Universidad Nacional, la creación de la Escuela Normal Superior y la Revista de Indias, son los tres pilares sobre los que se sustentaba la gran reforma de la Educación colombiana enmarcada dentro de la llamada "Revolución en Marcha" patrocinada por el liberalismo en el poder y por su presidente López Pumarejo de manera personal.

Los dos primeros años de la revista son un tanto parecidos a los de su antecesora Senderos, pero para 1938 al coincidir con la llegada de los primeros ibéricos exiliados, la revista experimenta una sacudida que tiene como disparo de salida la conmemoración de los 400 años de la fundación de Bogotá, en que escritores de los dos lados del Atlántico decidieron darle un sesgo internacional a la revista conformando su comité editorial españoles exiliados llegados a Colombia, que huyeron de la ya ineludible derrota de las armas gubernamentales en España, como: José Cuatrecasas, Luis de Zulueta o José María Ots Capdequí, todos ellos guiados por el director de la revista, Germán Arciniegas, quien después fungiría como ministro de Educación y desde ese puesto como protector de exiliados españoles.

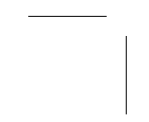


Hernandez_revista latinoamerica 06/06/12 11:54 Página 147

La INFLLENCIA PEDAGÓGICA DEL EXILIO REPUBLICANO ESPAÑOL: LA EDAD DE ORO DE LA ENSEÑANZA EN COLOMBIA

Las inquietudes de los exiliados están consignadas en la revista a través de artículos que denotan las preocupaciones trascendentales y vitales de los mismos y la plasmación de sus saberes académicos que aunque ya demostrados en Europa, no habían sido descubiertos y compartidos en Colombia.

José Cuatrecasas Arumí publicó algunos artículos de pensamiento político, aunque su área de saber era la botánica, sobresale el trabajo "Colectivismo e individualismo". Recordemos que a la par que colaboraba en la revista como autor, también era miembro del comité de redacción.

Otro colaborador de la revista fue el poeta Enrique Diez Canedo, escritor con experiencia tras haber trabajado en la revista Tierrafirme, publicación fundada en 1935, durante la Segunda República en España y que sirvió para promover los estudios americanos en España, publicando textos de Röpke, Huizinga y Mannheim. Diez editó algunos artículos en la Revista de Indias, entre los que resaltan "Perfiles de Sor Juana Inés de la Cruz" por su profundidad y los trabajos alrededor de la pintura española "De Goya a Picasso" y "Goya, iniciador del Arte Moderno". Algún tiempo trabajó en el diario Sol de Madrid como crítico de teatro, cuyo interés se refleja en su artículo "De los espectáculos, el teatro y sus enemigos".

Luis de Zulueta, quien también formó parte del comité editorial, publicó algunos artículos en la Revista de Indias de temática internacional, igual que lo hacía de manera simultánea en el principal periódico del país, El Tiempo, "1940, un año decisivo" y "América frente a Europa", este último publicado en 1939.

Otros exiliados colaboraron con esta Revista de Indias, que bajo la batuta del maestro Arciniegas, se convirtió en referente del pensamiento histórico, sociológico y filosófico de Colombia e inclusive de América Latina.

\section{La EScuela Normal Superior}

Si hubo una institución educativa que acogió a los exiliados españoles fue la Escuela Normal Superior. Esta entidad se había hecho necesaria para surtir, sobre todo a la estatal Universidad Nacional de docentes suficientemente cualificados, déficit que existía en la Academia Colombiana hasta ese momento.

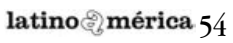

(MÉxico 2012/1): 135-153 147 
Hernandez_revista latinoamerica 06/06/12 11:54 Página 148

José Ángel Hernández García

Como lo expresan en el excelente trabajo sobre esta institución Marta Herrera y Carlos Low, "la Normal" tenía como objetivo principal profesionalizar a los maestros, hasta ese momento ocupados en compartir generalidades con los alumnos sin ningún aporte científico de enjundia y mucho menos de investigación. ${ }^{14}$

La tradición de la Escuela Normal Superior sería comparable a la de la Institución Libre de Enseñanza española y aunque la colombiana tenía en un principio como ejemplo a sus homónimas en Alemania y Francia, el aporte de los exiliados españoles se hizo notar en la mente y el ánimo de algunos de los gestores de la Escuela Normal Superior.

Lo que sí es claro es que el azar de la Guerra Civil española y la Segunda Guerra Mundial fue providencial para hacer posible la llegada de foráneos que aportaron su experiencia para hacer posible la tarea de cambio pedagógico integral, lo que difícilmente hubiera sido posible con el único elemento autóctono.

La llegada, forzada por las circunstancias bélicas en su país, de exiliados españoles con características laborales e intelectuales que pudieran cubrir la demanda de verdaderos profesores fue providencial para la Colombia de los años treinta y representó un renacimiento cultural sin parangón en la moderna historia colombiana. Junto a lo mencionado, el patronazgo del presidente liberal Santos hizo que los exiliados fueran recibidos con las manos abiertas, lo que sin lugar a dudas no hubiera sido así con un gobierno conservador en el poder.

Una carencia evidente dentro de la Academia Colombiana era la de profesionales académicos dedicados a las ciencias técnicas y científicas, lo que se intentó paliar con la contratación de profesionales extranjeros entre los que destacaron una importante cantidad de exiliados republicanos españoles que fueron "reclutados" en distintos países, donde el forzado exilio los radicó, en su mayoría en Francia. A manera de resumen, destacaré los más descollantes, algunos de ellos ya referidos: Mercedes Rodríguez Bellido fue contratada por la Es-

${ }^{14}$ Marta Herrera y Carlos Low, Los intelectuales y el despertar cultural del siglo. El caso de la Escuela Normal Superior: una bistoria reciente y olvidada, Santa Fe de Bogotá, Imprenta Nacional, 1994.

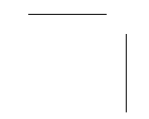


cuela Normal Superior como consecuencia del decreto 1039 que establecía la creación, dentro de la Escuela Normal, del Instituto de Psicología Experimental. Esta profesional de la psicología que mantuvo una relación epistolar con Freud en el pasado, introdujo la psicotecnia en Colombia, algo innovador hasta este momento en el país. Su test para los nuevos aspirantes de ingreso a la Universidad sentó las bases del sistema actual de selección universitaria en Colombia.

Antonio García Banus al llegar a Colombia ya era un químico renombrado en su gremio. Había sido catedrático en La Sorbona, donde lo reclamó el presidente Santos, su llegada a Colombia representa un antes y un después en la enseñanza de la química en Colombia. En 1938 fue nombrado director del novedoso Departamento de Química de La Universidad Nacional, que en un principio estaba situado en el sótano de la Facultad de Medicina. A la perseverancia de García Banus se debe el reconocimiento del estatus de carrera de la Química en Colombia, cuyo primer decano fue él. Su gran contribución a la química estuvo a punto de ser reconocida en un nivel mundial con su candidatura al Premio Nobel. En 1946 decidió abandonar Colombia y marchar a Venezuela donde suponía encontrar un ambiente más propicio para desenvolverse social y laboralmente.

José Cuatrecasas Arumí es otro de los destacados científicos que eligió Colombia para su exilio, tras la derrota de la República en España. Cuatrecasas ya era conocido en Colombia, donde había acudido en 1932 como representante del Estado español en la efeméride del centenario de José Celestino Mutis, por lo que la concesión de su visa se dio sin problemas.

Sus trabajos sobre la flora colombiana se generaron en la Universidad Nacional, concretamente, en el Instituto Botánico, como profesor de Botánica hasta 1947. En este año emigró a Estados Unidos al conseguir un contrato en el Smithsonian Institute y en el Museo de Historia Natural de Chicago. Se le reconoció su labor en Colombia con la concesión de la Cruz de Boyacá en 1959.

José de Recasens Tuset fue otro prominente representante del exilio español en la Escuela Normal Superior. Llegó a Colombia sin los estudios de arquitectura terminados, lo que no fue óbice para que se reconociera su sapiencia. Trabajó también como profesor en la Escuela de Arquitectura de la Universidad 
Hernandez_revista latinoamerica 06/06/12 11:54 Página 150

José Ángel Hernández García

Javeriana de Bogotá. Su polifacética preparación hizo que impartiera clases de Filosofía y Psicología en la Facultad de Comunicación de la misma universidad, en la Nacional y en la de los Andes, en esta última como decano de Antropología. A partir de 1974 fungió como director de la Facultad de Diseño Industrial de la Universidad Jorge Tadeo Lozano de Bogotá, cargo que abandonó para convertirse en decano de la Facultad de Periodismo de la Universidad Externado hasta 1990, año en que falleció.

Pedro Urbano González de la Calle había sido por oposición catedrático de Latín y Sánscrito en la Universidad salmantina, así como vocal del Consejo Nacional de Cultura. Con su llegada a Colombia su peripecia laboral no cambió drásticamente ya que se dedicó a enseñar Latín, Sánscrito y Lingüística en las principales instituciones de Educación Superior de Colombia.

Miguel Fornaguera es otro ilustre pedagogo que colaboró con la formación de docentes en la Escuela Normal Superior. Participó en la creación y elaboración de los estatutos del Gimnasio Moderno de Bogotá, institución de enseñanza de la clase alta bogotana, también fue vicerrector de la Universidad del Cauca y rector de la de Popayán.

En el Instituto de Educación Física se forjó su fama de competente el médico Pedro Mayoral Carpintero, quien consiguió para aquel el grado de Facultad y dirigió hasta 1946. No podemos dejar de mencionar en este trabajo a José María Ots Capdequí, ilustre americanista y más concretamente fino conocedor de las instituciones indianas. Su España en América: las instituciones coloniales escrito y publicado en Colombia es prueba de ello. Volvió a España en 1953 donde se le restituyó su cátedra en la Universidad de Valencia en 1963, poco antes de jubilarse.

Fernando Martínez Dorrien fue uno de los primeros exiliados a Colombia y contribuyó de manera especial a la difusión cultural con la fundación de la revista Estampa, la primera en utilizar el huecograbado en Colombia; José de Benito, catedrático de Derecho Mercantil en España, laboró en el periódico bogotano El Tiempo, propiedad de la familia Santos, cuando volvió a España recobró su plaza en la Universidad de Zaragoza; Felipe Andrés Cabezas había sido profesor de Literatura en la Universidad de Salamanca, especialista en Luis Vives, en Colombia fue profesor de Lengua española en Ocaña, departamento del 
Hernandez_revista latinoamerica 06/06/12 11:54 Página 151

LA INFLUENCIA PEDAGÓGICA DEL EXILIO REPUBLICANO ESPAÑOL: LA EDAD DE ORO DE LA ENSEÑANZA EN COLOMBIA

Norte de Santander; Antonio Fabra Rivas, sociólogo, fue profesor de la Universidad del Cauca y de la Escuela Superior de Agricultura de Colombia; el catalán Francisco del Olmo Barrios fue jefe de Educación Pedagógica de la Dirección de Educación Nacional del Atlántico y profesor de la Escuela Industrial de Barranquilla; Santiago Sentis Melendo, magistrado en España, fue docente del colegio Colón de Barranquilla, en Colombia; Ignacio Vidal Guitart fue director de la Escuela de Agricultura de Cali; Marco Aurelio Vila fue profesor en la Universidad de El Rosario y director de varios internados en Bogotá. El geógrafo Pau Vila i Dinarés fue profesor en la Universidad Nacional; Pablo Ardila, geógrafo, elaboró la Primera geografía con parámetros modernos en Colombia, también impartió clases en el prestigioso Colegio Mayor San Bartolomé de la capital colombiana; José Francisco Cirre, profesor de Literatura en la Escuela Normal Superior, marchó a Estados Unidos junto con su esposa, Manuela Manzanares, quien trabajó en la Biblioteca Nacional de Colombia; Pedro Villa fue el primer rector del más prestigioso centro de enseñanza primaria y secundaria, el Gimnasio Moderno; Manuel Usano Martín, cirujano, quien había sido profesor ayudante en la Universidad de Valencia, en Colombia, fue profesor de la Escuela Normal Superior. El galeno Carlos Zozaya Balza fungió como titular de Parasitología y Enfermedades Tropicales en la Universidad Pontificia Javeriana y en la Universidad Nacional, terminó como profesor en la Autónoma de Caracas; el arquitecto Esteban de la Mora, quien construyó y proyectó la Plaza de Toros de Bogotá, fue profesor de Urbanismo en Bogotá; los hermanos Manuel y Enrique García Reyes trabajaron como profesores en la Escuela de Ingenieros de Bogotá. Antonio Fabra Rivas, uno de los organizadores de la Semana Trágica de Barcelona en 1909, fue profesor de la Universidad de Popayán, en Colombia.

\section{CONCLUSIÓN}

Llama la atención el hecho de que en la bibliografía disponible sobre el exilio republicano como consecuencia de la Guerra Civil española, el caso colombiano sea prácticamente desconocido, y aún más, el de los profesores y pedagogos, que 
Hernandez_revista latinoamerica 06/06/12 11:54 Página 152

José Ángel Hernández García

sentaron los pilares educativos en un país hasta ese momento indolente respecto a los asuntos pedagógicos y académicos.

La coincidencia de un gobierno liberal en Colombia, simpatizante de los que habían perdido la guerra en España y la disposición, como consecuencia de ello, de un número importante de profesores e intelectuales expatriados, llamando a la puerta de cualquier país que les ofreciera refugio, se aunaron para poder disponer de un contingente humano que intelectualmente no tenía parangón en Colombia y del que se podía disponer casi sin inversión previa de ningún tipo.

Lo expuesto no evita la crítica de gobiernos liberales a los que llenándoseles la boca de internacionalismo y solidaridad, fueron muy restrictivos con la llegada de estos profesionales foráneos de la educación, a los que no se les negaba su alta cualificación laboral, pero a los que se suponía un bagaje político cuando menos comprometido con ideologías de izquierda consideradas peligrosas para un gobierno liberal acosado y acusado de fomentarlas por la oposición conservadora y una parte importante de la opinión pública.

Otros españoles que recalaron en Colombia huyendo de la dictadura franquista como los anteriormente expuestos, merecerían ser mencionadas en este artículo. Todos contribuyeron con sus conocimientos y enseñanzas en Colombia al dejar bien alto el concepto de la pedagogía en España y de todos los españoles, sentando las bases de la actual estructura académica colombiana.

Como dijo al autor, quien fuera ministro de Educación en los años treinta, "fue la Edad de Oro de la educación en Colombia". Sirva pues este trabajo para reivindicar a todos y a cada uno de los españoles que nos precedieron en las aulas colombianas y que dejaron un listón muy difícil de superar.

Recibido: 22 de noviembre, 2011. Aceptado: 23 de enero, 2012.

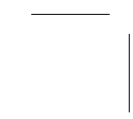


Hernandez_revista latinoamerica 06/06/12 11:54 Página 153

LA INFLUENCIA PEDAGóGICA DEL EXILIO REPUBLICANO ESPAÑOL: LA EDAD DE ORO DE LA ENSEÑANZA EN COLOMBIA

\section{BiBLIOGRAFÍA}

Jaramillo Uribe, J., "La educación en los gobiernos liberales 1930-1946", en Álvaro Tirado Mejía [dir.], Nueva Historia de Colombia, t. IV, Bogotá, Planeta, 1989, pp. 87-110.

Martínez GorroÑo, M. E., "La educación en la Colombia liberal de los años 30 y 40: la trascendente contribución del exilio español consecuencia de la guerra civil de 1936-1939", en Migraciones \& Exilios, núm. 4, 2003, Madrid, AEMIC, pp. 9-30.

Basurto Larrañaga, R. [coord.], Homenaje a Francisco de Abrisketa, Sociedad Bolivariana del País Vasco, 1993.

GIRAL, F., Ciencia española en el Exilio (1939-1989), Madrid, Anthropos, 1994. HeRnández García, J. A., La Guerra Civil española y Colombia. Influencia del principal conflicto mundial de entreguerras en Colombia, Bogotá, Carrera 7ª/Universidad de La Sabana, 2006.

J. A. "iAy de los vencidos! El exilio y los países de acogida", en Mateos Abdón [ed.], El exilio español republicano en Colombia, Madrid, Eneida, 2009.

LLoRens, V., En la emigración republicana, Barcelona, Taurus, 1978.

ARósteguI, JuLIO, Historia general de la emigración española a América, vol. 1, Madrid, 1992.

BushnelL, David, Eduardo Santos y la política del Buen Vecino, 1938-1942, Bogotá, El Áncora, 1984.

Cabezas Sánchez-Albornoz, Sonsoles, Historia política de la República en el exilio, Madrid, Fundación Universitaria Española, 1997.

Palazón Ferrando, Salvador, Capital humano español y desarrollo económico latinoamericano, evolución, causas y características del flujo migratorio (1882-1990), Alicante, Generalitat valenciana/Consellería d'educacio i ciencia/Institut de Cultura Juan Gil-Alvert, 1995. 